\title{
Representation Meaning of Multimodal Discourse-A Case Study of English Editorials in The Economist
}

\author{
Jing Yang \\ Yanching Institute of Technology, Sanhe, Langfang, Hebei Province, China \\ Yi Zhang \\ Yanching Institute of Technology, Sanhe, Langfang, Hebei Province, China
}

\begin{abstract}
Resources such as images, colors, sounds and actions have already been regarded as different types of modes which fulfill the meaning-making. Multimodal discourse refers to two or more modes working together for the meaning-making of the whole discourse. With Kress\& van Leeuwen's Visual Grammar as the theoretical framework and based on Royce's inter-semiotic complementarity theory, the paper conducts a multimodal discourse analysis of English editorials in the Economist from ideational aspects. The study of ideational aspect focuses on factors such as participants, processes (action, reactional, etc.), circumstance, etc. The analysis reveals the pictures' functions in meaning interpretation and explains the relations between the pictures and the verbal texts. English editorial discourses usually possess multimodal characteristics displayed by two semiotic modes (visual mode and verbal mode). English editorials give almost equal weight to both their pictures and verbal texts. Since English editorials are mainly to explain, to judge and to comment on hot issues, both their pictures and verbal texts coexist and integrate with each other to accomplish these tasks. Therefore, pictures, as an important component of English editorials, also can encourage and help readers to actively and effectively understand editorials' main ideas and attitudes.
\end{abstract}

Index Terms - multimodality, editorial discourse, visual grammar

\section{INTRODUCTION}

As science and technology develop rapidly, the world enters an information era which is also an age of international communication. With wide application of digital technologies, internet and multimedia, meaning-making rarely depends on language alone. Image, color, sound and action symbol which have been considered as paralanguage no longer play a subordinate role in modern communication. Combined with linguistic discourse, the paralanguage is also incorporated into semiotic resources for meaning-making jointly. For example, advertisements, posters, textbook, newspaper, etc usually include two or more different semiotic modes such as images, sound and language, etc. These different systems or possible "channels" (e.g. speech, writing, and images) which achieve meaning-making practices are identified as semiotic modes. Thus, some meaning-making practices or communicative events present the multimodality.

Just as Lim (2004) said that "we live in a multimodal society, which makes meaning through the co-employment of semiotic resources" (p.52). Nowadays, multimodal communication, instead of monomodal communication, has become the mainstream of communication of human beings. The majority of newspapers and magazines add visual images concerned with the contents of newspaper and magazine articles with the aim of helping readers have a thorough understanding of topics and contents of newspaper and magazine articles. These visual images such as pictures, photos and caricatures, etc are adopted to transmit the information of newspaper and magazine articles. Multimodality is one of characteristics embedded in these discourses.

As much attention has been paid to multimodal discourse, there is an urgent need to analyze how visual images function in the meaning making of the discourse on the condition that two semiotic resources are used together. Based on Halliday's Systemic-Functional Grammar and Kress and van Leeuwen's Visual Grammar, and with Royce's inter-semiotic complementarity framework as a research tool, taking editorials in the Economist as examples, the paper will conduct a multimodal discourse analysis of English editorials in western press, analyze and discuss how visual images converge with verbal texts in the multimodal discourse to reflect social reality and culture.

\section{Editorial Discourse}

According to Wikipedia, an editorial is "an opinion piece written by the senior editorial staff or publisher of a newspaper or magazine". It is usually unsigned and also called "leading articles" or "leader". Editorials in western press usually belong to 'opinion' section, whose topics ranges from politics, economy to military operations. As the author of 
Editorial Writing, M. Lyle Spencer(1924) defined it as "a presentation of fact and opinion in concise, logical, pleasing order for the sake of entertaining, of influencing opinion, or of interpreting significant news in such a way that its importance to the average reader will be clear" (p.16). William Pinkerton once summarized the four purposes of editorials which were published in the Nieman Report. Then, Rivers (1988) paraphrased as follows:"(1) Explaining the news; (2) Filling in background;(3) Forecasting the future:; (4) Passing judgment"(p.25). The above-mentioned definitions only point out the functions and purposes of editorials rather than their composition. The previous researches mostly focus on single-mode editorials or the text part of editorials rather than other semiotic codes existing in editorials. Multimodal editorials refer to those editorials involving two or more modes. Editorials with visual and verbal modes are the mostly commonly seen in daily life.

\section{Multimodal Discourse Analysis of Editorials in Western Press}

The author collects 13 samples from online The Economist, involving various topics, such as politics, society, culture and economy. These samples are mainly chosen from the magazines of the 2010 and 2011 year. They are applied as specific examples in our discussion so as to explore the representation meaning of visual images and the relationship between visual images and verbal text with images and explain how visual images and verbal text combine with each other to expose meanings.

\section{A. Systemic-functional Grammar}

Halliday holds that language is perceived as social semiotic in his Systemic-Functional Theory. He develops systemic-functional grammar in the 1960s, which is part of a broad social semiotic approach to language in which language is considered as a socially-based semiotic system. He believes that language incorporates three metafunctions. Generally speaking, the three metafunctions are principles that semiotic resources simultaneously present a method for constructing ideational meaning and for fulfilling social relations. These principles then could organize discourse, which is the textual meatafunction. Thus, ideational metafunction refers to the representation of different experience processes in reality, which is realized by transitivity system and relates to the field aspects of a text. Interpersonal metafunction indicates that when communicating with others, people exchange their feelings, attitude and judgments by means of mood and modality. It matters a text's aspects of tenor or interactivity. Textual metafunction, which concerns mode, focuses on how to use language to organize a cohesive text and "establishing continuity in time and space" (Halliday, 1978, p.60) through thematic structure and information structure. In a word, the three metafunctions laid a foundation for verify the functionalities of semiotic resources.

\section{B. Visual Images}

In recent years, Kress and Van Leeuwen take a view of Halliday's systemic-functional grammar to study visual images. They consider Halliday's three metafunctions as a main tool to analyze any human communication system. Though three metafunctions at first are applied to study language, they do not only focus on language signs. Scholars such as Kress and van Leeuwen also extend their study on discourse including visual images. Kress \& van Leeuwen (1996) also suggest that "the visual, like all semiotic modes, has to serve several communicational (and representational) requirements, in order to function as a full system of communication" (p.40). They develop Visual Grammar for further study. Kress and Van Leeuwen's Reading Images: The Grammar Of Visual Design (2006) introduces Visual Grammar, which is a clear multimodal approach to visual communication and gives a thorough and systematic illustration of the grammar of visual design. They named representational meaning, interactive meaning and compositional meaning in correspondence with Halliday's ideational, interpersonal and textual metafunctions.

Representational Meaning

"Any semiotic mode has to be able to represent aspects of the world as it is experienced by humans. In other words, it has to be able to represent objects and their relation in a world outside the representational system" (Kress \&Van Leeuwen, 2006, p.42) corresponding to Halliday's ideational metafunction, visual grammar introduces representation meaning which functions well in visual mode. Objects or elements existing in visual images will be called "participants" which compose of people, place and things of various kinds represented in and by images. Actually, every semiotic act comprises two types of participants, one is interactive participants and the other is represented participants. Interactive participants are those in the act of communication, "who speak and listen or write and read, make images or view them" (Kress \&Van Leeuwen, 2006, p.48). Represented participants mention those "who constitute the subject matter of the communication; that is, the people, places and things (including abstract 'things') represented in and by the speech or writing or image, the participants about whom or which we are speaking or writing or producing images" (Kress \&Van Leeuwen, 2006, p.48).

Representational meaning can be classified into two categories: narrative representations and conceptual representation.

a. Narrative Representation

Narrative representation refers that "when participants are connected by a vector, they are represented as doing something to or for each other" (Kress \&Van Leeuwen, 2006, p.59). Such kind of vectorial patterns focus on illustrating "unfolding actions and events, processes of change, transitory spatial arrangements"(Kress \&Van Leeuwen, 2006, p.59). 
Vector, as the distinctive feature of narrative processes, is usually realized by elements appearing in pictures that form "an oblique line, often a quite strong, diagonal line"(Kress \&Van Leeuwen, 2006, p.59). Take the following sketch (Fig. 1) as an example; the man in blue pushes the red ball with his hands. His outstretched arms and hands form a vector. Actually, vectors can be reflected by various ways, such as human bodies or tools in action.

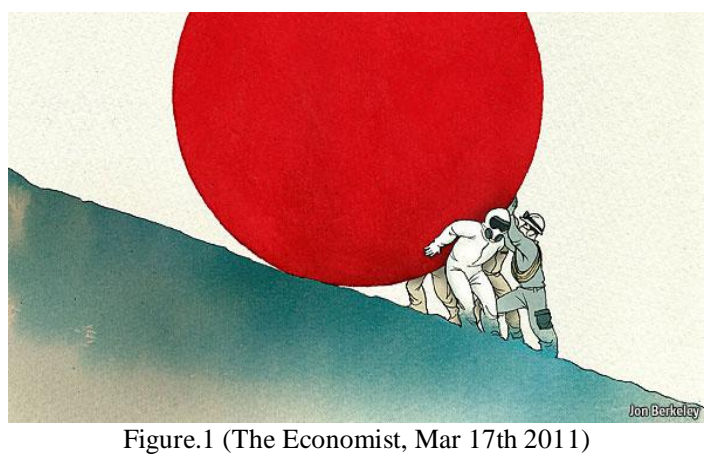

Based on the kinds of vectors and the number and the kind of participants included in visual images, different kinds of narrative processes could be distinguished. It is mainly concerned with action, experience and events, mainly including action process, reactional process and speech and mental process.

1. Action Processes

In narrative process, one participant from which vector departs is named "Actor". If visual images only include one participant, it is usually an Actor. The process is non-transactional in which action has no Goal and "is not 'done to' or 'aimed at' anyone or anything"(Kress\& van Leeuwen, 2006, p.63). However, the transactional structure consists of both Actor and Goal. Goal is "the participant at whom or which the vector is directed"(Kress\& van Leeuwen, 2006, p.64).

Sample 1 is an example of action process (Fig.2).

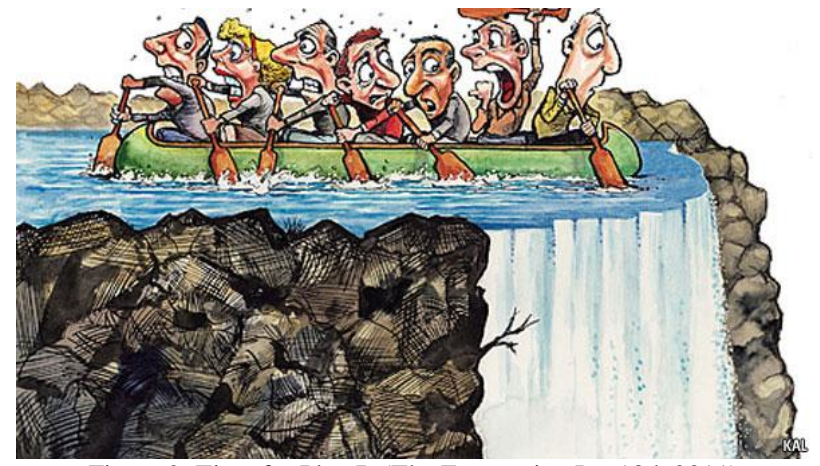

Figure 2. Time for Plan B (The Economist, Jan 13th 2011)

In Sample 1, seven persons sitting in one boat are in a dreadful plight. Behind them was a torrential waterfall. They row against the current with all their strength. The left four persons spare no pains rowing in hope of preventing the boat from being washed away. The rest three persons seem to be more nervous and more frightened than the left four ones. They have already approached the danger. In this sample, six persons are the Actor. Their paddles act as the vector by forming the oblique lines with the current (the Goal). These action processes are transactional. Besides, another action process is expressed by the running waterfall. It is a non-transactional process that is not instigated by persons or things and has no Goal. Therefore, non-transactional action process is analogous to the intransitive verb in language.

The verbal text of Sample 1 discusses that after the failure of Europe's bail-out strategy; plainly insolvent European countries need to conduct debts restructuring to get rid of sovereign-debt crisis. Combined with analysis of recent situation in several European countries, they still have a fighting chance of putting the crisis behind them if they choose to restructure their debts.

Seven people represent seven European countries (Portugal, Belgium, Spain, Greece, Ireland, Italy, and Germany) trapped in the sovereign-debt crisis. The waterfall indicates this crisis. If these countries do not take urgent actions, they would be washed away.

The sketch firstly attracts readers' attention and makes them wonder in mind what it implies. With this question in mind, readers can quickly grasp the main idea of verbal text and have a deep impression. Thus, the sketch aids readers in understanding the verbal part and demonstrates the main idea of verbal text vividly.

Sample 2 is an example of action process in which the Actor is unknown (Fig. 3). 


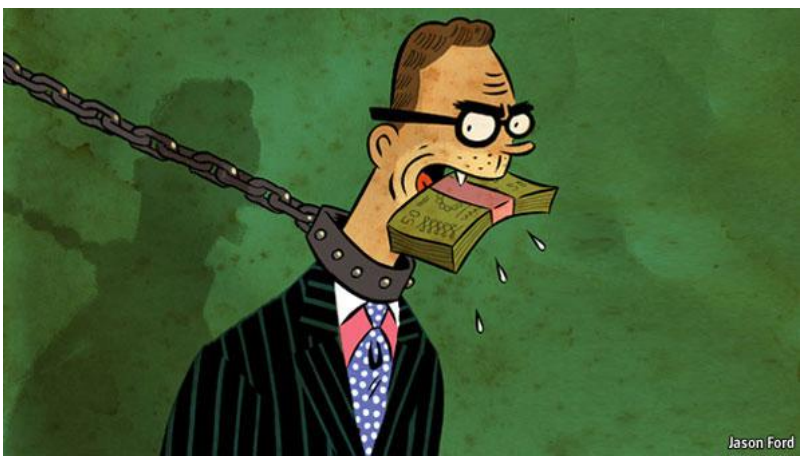

Figure 3. Unfinished Business (The Economist May 12th 2011)

In Sample 2, a man wearing a suit is shackled by an iron chain. He snaps a stack of money in his mouth and stares at the viewers. He looks very angry and dissatisfied. The viewers could not be aware of who bind this man. Only the iron chain (vector) and this man (Goal) emerge in this image.

The essay mainly talks about how to fix problems existing in international banking to make it safer and how to relieve taxpayers' hardship. In face of the financial crisis, bankers gather together to discuss how to hold a lot more capital to protect banks against unexpected losses.

In this picture, the man bound by the iron chain indicates the taxpayer is still trapped in loss although he has a thick buffer of equity and convertible debt in hand. No one knows who bind him. As readers see this sketch, they are curious about who bind this man and why this man is bound by the iron chain. There is no doubt that his condition is in desperate straits. As readers skim through the verbal text, they can create a clear and vivid picture in their mind.

\section{Reactional Processes}

The process is reactional in which "the vector is formed by an eyeline, by the direction of the glance of one or more of the represented participants"(Kress\& van Leeuwen, 2006, p.67). It contains two components: reactor and phenomena Reactor is one who conducts the looking behavior. It could be human or a human-like animal. Phenomenon is "the participant at whom or which the reactor is looking" (Kress\& van Leeuwen, 2006, p.67).

Then, Sample 3 is an example of transactional reactional process (Fig. 4).

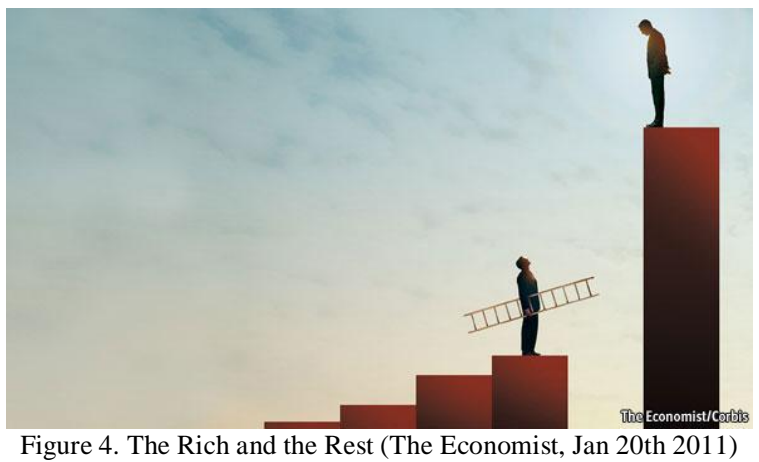

In this picture, one man stands on the lower stairs while the other man is in a higher place. Both of them look at each other. The man in lower place holds a ladder in his hand (this is a transactional action process in which the man and ladder are Actor and Goal respectively). His dream is to reach the place where the other man stands. Meanwhile, gazing at the man in lower place, the man in higher place is observing how the man in lower place takes action. The eyeline between the two men is the vector which indicates the whole process is reaction. The man in higher place acts as the Reactor while the transactional action structure plays the role of phenomenon.

Sample 3 verbally talk about the dangers of a rising gap between the rich and the rest in various countries and arguments about inequality. Then, it discusses how to improve such condition.

The one in the higher place is the representative of the rich while the one on the lower stairs is on behalf of the rest. Although the one in the lower place has a ladder in his hands, he still can not reach the higher place. The gap between two men indicates the rising inequality. By this picture, readers guess that there is a comparison between two men. They also find out that the man in the lower place has difficulty in overcoming this existing gap. Readers gain useful information from the picture. Then, they would have a better understanding of the verbal text.

Sample 4 is an example of non-transactional reactional process (Fig. 5). 


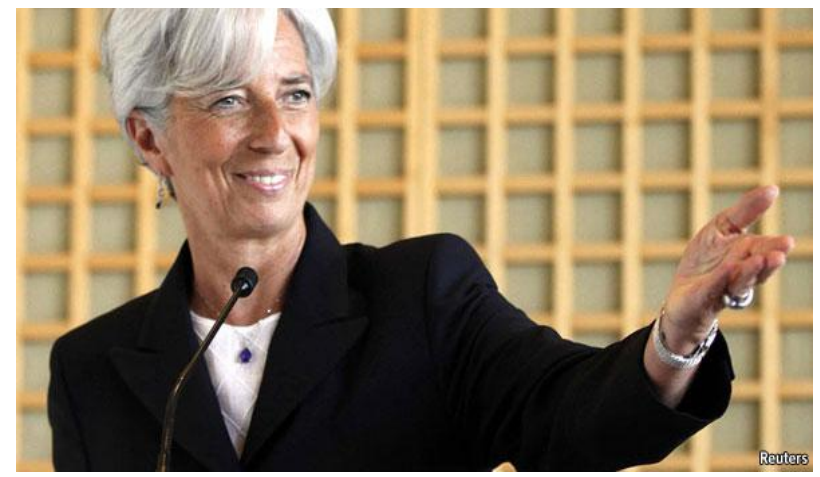

Figure 5. Time for A Change (The Economist, May 26th 2011)

Sample 4 displays a lady looking at the left side with a smile on her face. Her left arm keeps a "please" position. Her smile and gesture show her high degrees of adaptability. Although the corresponding phenomenon had not displayed before the viewers, this lady show her attitude and expects to communicate with others. The direction of her gaze represents the vector. Only the Reactor (the lady) comes forth in this sample. Such condition gives the viewers an opportunity to imagine what this lady are looking at. In that sense, it creates a strong sense of empathy or identification with the represented participations.

3. Speech Process and Mental Process

A special vector appears in comic strips, quotes in school textbooks, on the screens of automatic bank tellers, etc. "The oblique protrusions of the thought balloons and dialogue balloons that connect drawings of speakers or thinkers to their speech or thought"(Kress\& van Leeuwen, 2006, p.68).

Sample 5 is an example of speech and mental process (Fig. 6).

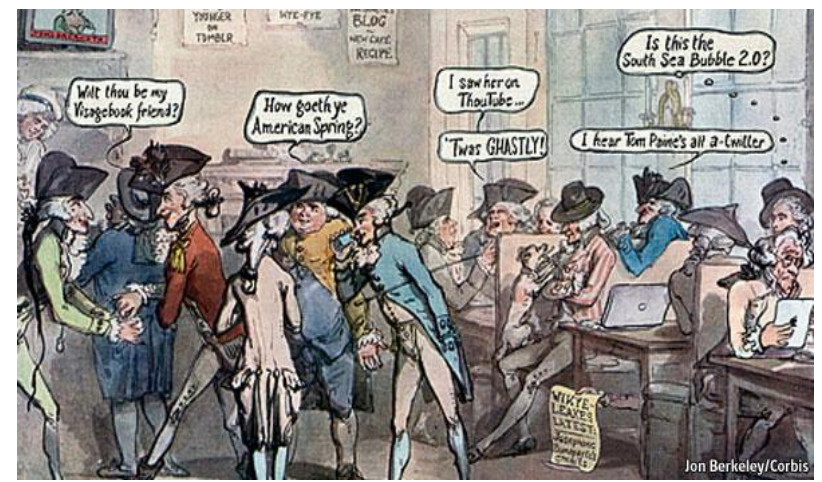

Figure 6. Back To the Coffee House (The Economist, Jul 7th 2011)

Sample 5 illustrates speech and mental process by presenting different persons with various opinions. These persons chat in a room (like cafe). Two or three of them gather together and talk about various topics. It seems to indicate that much more people discuss diverse topics in public places.

Sample 5 refers that internet take news industry back to the coffee house, a diverse, argumentative and stridently alive environment. It also points out two areas of concern and provides some useful advice.

The sketch recreates the scene in the coffee house with a number of people gathering and chatting with each other. The dialogue balloons suggest their conversations with different topics. As readers has an impression of a coffee house from the sketch and then read the verbal part, they would recognize the similarity of information dissemination in the coffee house and on the internet.

Circumstances

Narrative process may present some participants not in the form of vectors but in other means. They are not the main participants but without them narrative processes may lose some information. They are circumstances which are subdivided into setting (locative circumstance), means (tools), and accompaniment. In Sample 4, compared with this lady, the background has softer focus, because the background is setting. Then, this lady extends her arm to an unseen participant. She delivers her attitude to the unseen participants with her hand. Her hand is a circumstance of means.

In Sample 6 (Fig. 7), two ladies and two men stand in one line and look towards the viewers with big smiles. No vector links these four participants up. So their relations can be interpreted as accompaniment. 


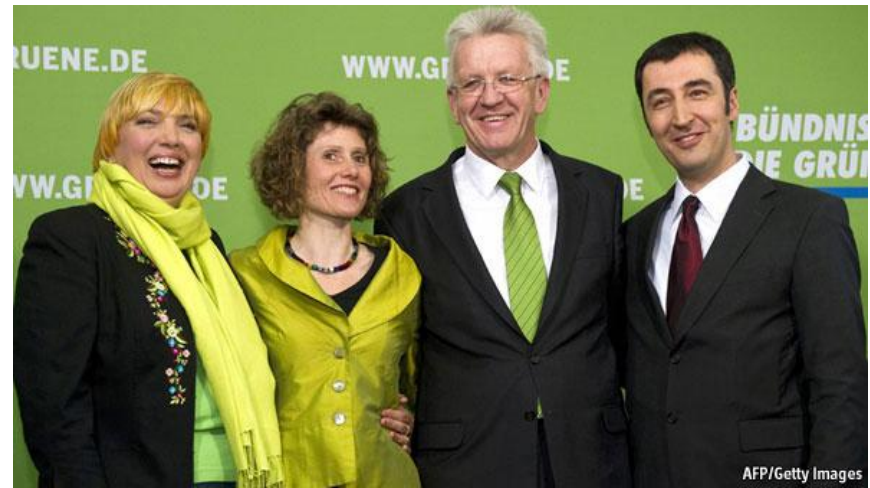

Figure 7. A Green Revolution (The Economist, Mar 31st 2011)

b. Conceptual Representation

Conceptual representation is a non-narrative process involving "representing participants in terms of their more generalized and more or less stable and timeless essence, in terms of class, or structure or meaning" (Kress\& van Leeuwen, 2006, p.79). Compared with narrative representation, conceptual representation has no vector and also has three structures involved.

1. Classificational Process

"Classificational processes relate participants to each other in term of a 'kind of' relation, a taxonomy: at least one set of participants will play the role of Subordinates with respect to at least one other participant, the Superordinate" (Kress\& van Leeuwen, 2006, p.79). As viewers could figure out the superordinate from the similar features visually existing between subordinates or only verbally in the accompanying text, this structure is covert taxonomy. This structure connects participants with each other by equal distance when these participants are in same size and the same direction towards the horizontal and vertical axes.

In overt taxonomies, one participant would be superordinate for some of other participants while it also would be subordinate with respect to others. Such kind of participants can be called "interordinate". In other words, level is another characteristic of overt taxonomies on same which participants, to some extent, possess the same peculiarity.

Sample 7 (Fig. 8) is an example of classificational process, which indicates an ordering and usually includes two participants: subordinates and superordinates.

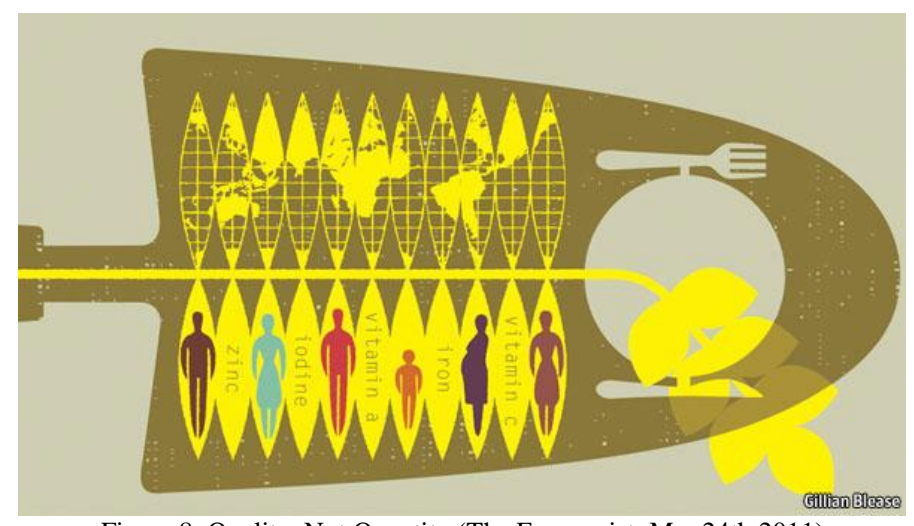

Figure 8. Quality, Not Quantity (The Economist, Mar 24th 2011)

In Sample 7, spindle-shaped elements at the bottom represent diverse nutritive substances and people of different age groups and skin colors. Both these persons and nutritive elements are subordinates. As for these six persons, their superordinate is the human being all over the world. Meanwhile, zinc, iodine, vitamin a, iron, vitamin c can be generally designated as nutritive elements that are vital to human health. With equal space left in every two spindle-shaped elements, same size of each element and same direction towards the horizontal and vertical axes, this classificational process is covert. In covert taxonomy, the similarities between subordinate elements could be concluded by viewers or be indicated in accompanying text. Therefore, superordinate usually can be presumed.

2. Analytical Process

Analytical processes connect participants in terms of a part-whole structure. Two participants involved in these processes are respectively one Carrier (the whole) and any number of Possessive Attributes (the parts).

Sample 8 (Fig. 9) is an example of exhaustive analytical process, which is a part-whole structure, involving two participants: one Carrier (the whole) and several Possessive Attributes (the parts). 


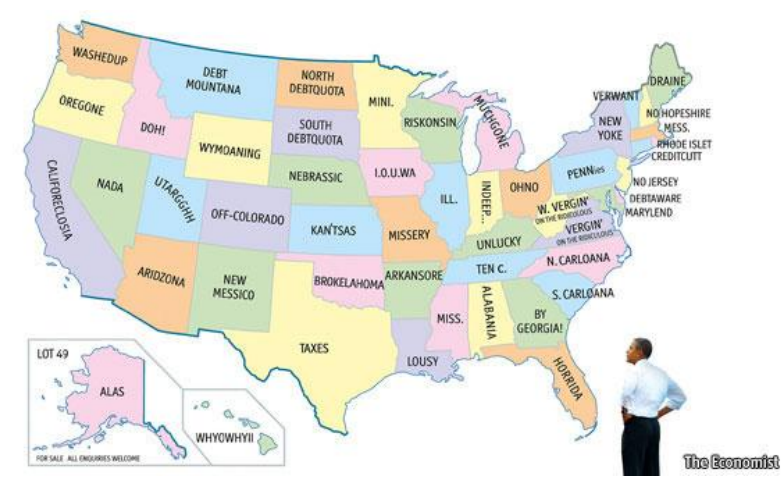

Figure 9. The Union's Troubled State (The Economist, Jan 27th 2011)

In the visual mode of Sample 8, all possessive attributives occupy the whole space of the Carrier. The map of the United States (the Carrier) clearly marks the areas and names of all the states (the Possessive Attributes) with different colors and black words. This image provides not only the general geographical concept of America but also detailed geographical distribution of every state. From this image, viewers further understand the relative location of all states.

Sample 9 (Fig. 10) is an inclusive analytical process only displaying some of the Possessive Attributes rather than all of them. In this process, part of the space of the Carrier has been filled with certain possessive attributives. This process leaves the rest of the carrier unaccounted for and unanalyzed.

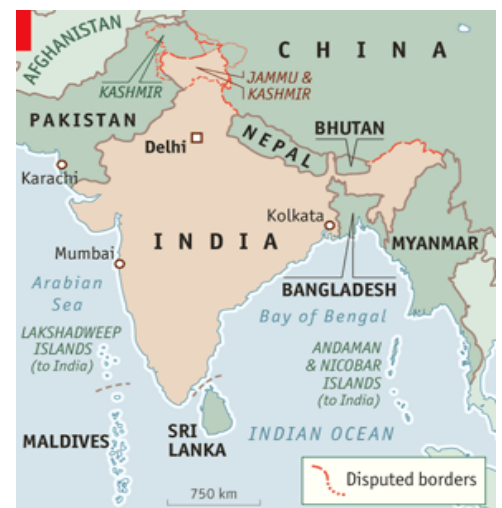

Figure 10. New Humility for the Hegemon (The Economist, Jul 30th 2011)

In Sample 9, Jammu\& Kashmir region which is marked by red lines demonstrates the inclusive analytical process. Pakistan and India are regarded as Carriers. Part of Pakistan and Indian Territory belong to this region. But the rest of two countries do not take up the space of this region. So the territory included in Jammu\& Kashmir region is equal to some of Possessive Attributes.

Sample 10 (Fig.11) is an example of spatio-temporal analytical structures.

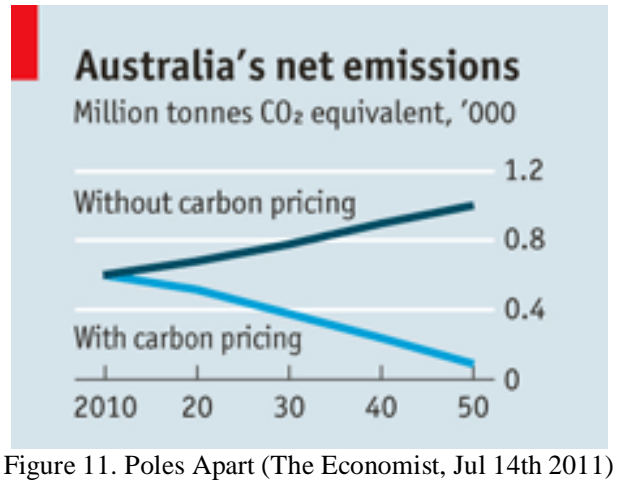

Such processes are two-dimensional charts with spatial and temporal axes. Therefore, these two-dimensional charts creates line graph to illustrate participants' dynamic movements. Usually such charts would show diverse actions such as change, grow, reduce, increase, decrease, etc. Line graphs transfer the analytical processes that underlie the graphs into dynamic processes. In Sample 10, originally, Australia's net emissions are considered as the Carrier while the changes along an ordered timescale are perceived as Possessive Attributes. However, such line graph finally pays more attention to describe the development of Australia's net emissions from 2010 to 2050 under the context of "without 
carbon pricing" and "with carbon pricing". According to the chart, in this fixed period of time, Australia's net emissions will increase in the condition of "without carbon pricing". The growth trend is reflected by an oblique line from lower left point (2010) to higher right point (2050). On the contrast, in the same period, Australia's net emissions will decrease under the situation of "with carbon pricing". Such condition is realized by another oblique line with opposite direction, compared with the growth line.

3. Symbolic Processes

Symbolic process focuses on what a participant means or is. If two participants are included in this structure, the Carrier achieves its meaning or fulfills its identity in this process while the Symbolic Attribute represents the meaning or identity itself. This type of structure is called symbolic attributive. If only one participant exists in this structure, it is the Carrier. This kind of process is named Symbolic Suggestive.

Sample 11 (Fig. 12) is an example of symbolic suggestive process which only has the Carrier.

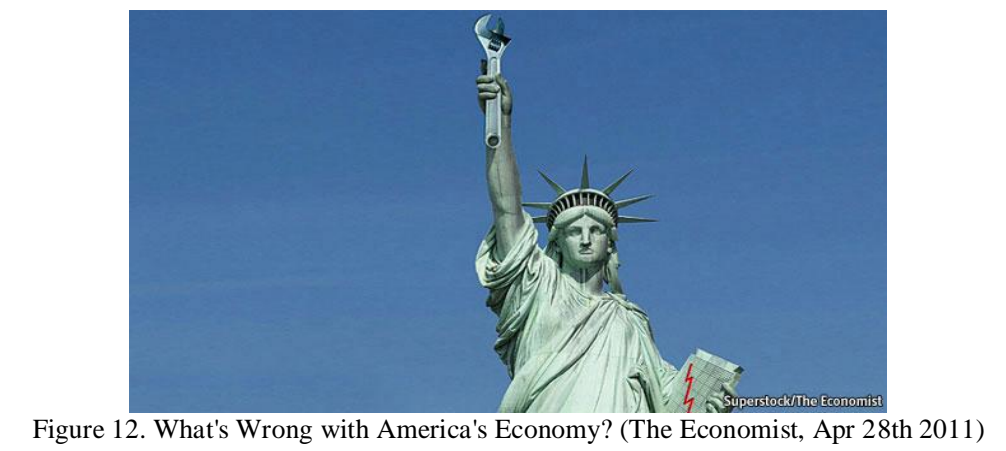

In Sample 11, the statue of liberty presented in the visual mode is the Carrier. It represents the United States. Although the viewers have no idea of the main topic, at their first glance at this picture, they know this article is related to the United States.

The verbal part of Sample 11 discusses the underlying obstacles that the America's economy faces, such as stagnating living standards, inability to create enough job opportunities, and big government deficit, etc. It also questions measures that President Obama takes to tackle these problems.

In real world, the statue of liberty holds a torch in her hand. But in this picture, the statue of liberty holds a spanner in her hands, which indicates the solutions used to tackle the existing problems. The sliding line graph in the other hand of the statue of liberty represents economic problems existing in the United States.

This picture gives a brief introduction of American current economic situation and measures applied to deal with economic problems. Then, readers could gain detailed information from verbal text. It will be easily and quickly for readers to grasp editors' opinion on these difficulties which disturb America's economy.

Sample 12 (Fig. 13) is an example of symbolic attributive process including the Carrier and the Symbolic Attributes.

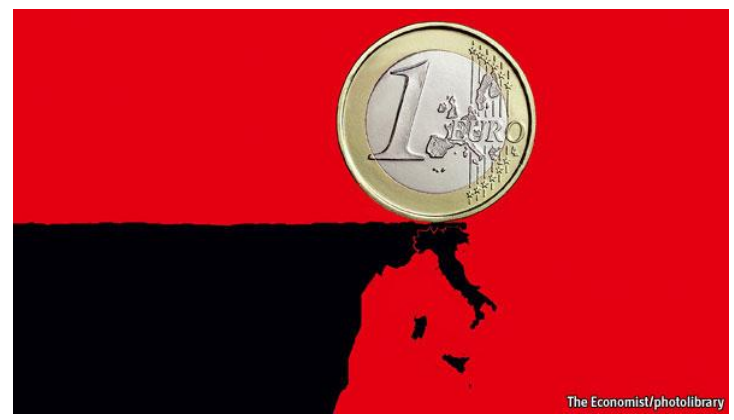

Figure 13. On The Edge (The Economist, Jul 14th 2011)

In Sample 12, one euro is put on the edge of a black cliff. It seems that the minor part of the cliff (the Carrier) could not stand the weight of one euro. It would collapse at anytime. In that case, the one euro would roll down. The shape of the minor part of the cliff is identical to the shape of Italy. So Italy is the Symbolic Attribute. On behalf of Italy, this minor part indicates the current situation that Italy is faced with difficulties and problems which Italy urgently needs to be resolved.

The verbal text of sample eleven introduces that Italy is facing debt crisis, whose default would have calamitous consequences for the euro and the world economy. Then, it presents the causes of crisis and some solutions. The minor part of the cliff vividly presents Italy's situation, whose position predicts the influence of Italy's default on euro zone. At the first sight of this picture, readers could know that its verbal content is related to Italy who is in a severe condition. Then, with this view, they further find out the main thought of verbal text.

\section{Ideational Inter-semiotic Complementarity}


To be specific, verbal texts achieve ideational metafunction through transitivity system. Visual images, such as naturalistic visuals (photos, sketches, etc.) and mathematical visuals (graphs, etc.), fulfill representational meaning through narrative processes and conceptual processes.

Visual structures and visual processes embodied in images are associated with various participant roles. These visual structures and processes reflect the reality, experience and information. Royce's ideational inter-semiotic complementarity refers that "the identification of represented participants (who or what is in the visual frame, either animate or inanimate), the represented processes or the activity (what action is taking place, who or what is the actor or is acting, and who or what is the recipient or object of that action), the circumstances, or what those actions represent according to the wider context of situation (these may be locative or concerned with the setting, of accompaniment in terms of participants not involved with the action, and of means in terms of participants used by the actors), and the attributes, or the qualities and characteristics of the participants" (Royce, 1998a, p.70). Such features as participants, processes, circumstances, and attributes can be conflated into the visual message elements which characterize semantic properties. Corresponding to visual message elements, lexical items in verbal texts also produce a set of lexical inventories which can be explicated in view of linguistic concepts on cohesive attributes, such as repetition, synonymy, antonymy, hyponymy, meronymy. Collocation proposed by Halliday also can be used to interpret the ideational cohesive relations in multimodal text.

Editorials in the Economist involves two components, one is visual images (mostly sketch carricatures) while the other is verbal texts. Based on Royce's inter-semiotic complementarity framework, the following part selects one picture to conduct case study and discuss the interface between visual and verbal semiotic systems from ideational aspect.

Case Study-Sample 1

Sketch caricature is portrayed to represent familiar objects, entities, scenes, characters, or actions that are easily recognizable to the viewers. Such abstracted caricature embodies main features of represented participants and conveys particular attitude that the drawer intends to take. Usually, sketches transmit information by means of visual metaphors.

Ideational inter-semiotic complementarity is achieved by the examination of the identification of represented participants, the represented process (activity), the circumstances and the attributes. Several sense relations such as repetition, synonymy, antonymy, hyponymy, meronymy, collocation are applied to explicate the ideational cohesive relations between the visual and verbal modes in multimodal texts.

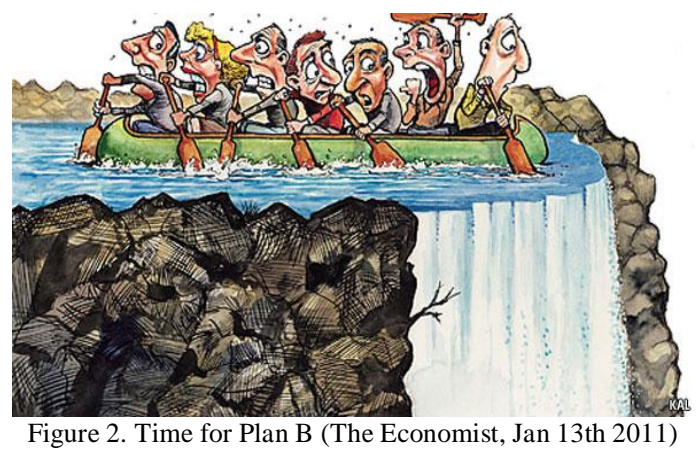

The verbal text of Sample 1 mainly discusses the restructuring of insolvent European countries' debts. As Europe's bail-out strategy (Plan A) is not working, there is an urgent need for Plan B which corresponds to the current situation of these European countries.

In the visual mode of Sample 1, represented participants are glossed as: seven people, which is verbally referred as seven European countries (Portugal, Belgium, Spain, Greece, Ireland, Italy, and Germany); the boat as a visual metaphor indicating the current situation of seven countries; and waterfall as a grim future (debt crisis). The process involved is rowing (debt restructuring), which is regarded as an action taken by seven people to avoid their boat to be washed away. It is also a visual metaphor. The Goal is to free from the danger. The circumstance is at the edge of the waterfall, which suggests the boat's present position (at the edge of waterfall) and future path (waterfall).

The following table would analyze the verbal and visual mode of Sample 1 and then discuss the inter-semiotic features. This table selects 17 key verbal sentences describing relative events, which happened in this visual sketch. It attempts to examine the represented participants (Actor and Goal), represented process (Process) and the Circumstance by which whether the visual and verbal modes could achieve ideational inter-semiotic complementarity or not. 
TABLE I.

LEXICO-SEMANTIC (IDEATIONAL) INTER-SEMIOTIC COMPLEMENTARITY-SAMPLE 1

\begin{tabular}{|c|c|c|c|c|}
\hline $\begin{array}{l}\text { Visual mode } \\
\text { S's } \\
\text { (verbal text) }\end{array}$ & $\begin{array}{l}\text { Actor: } \\
\text { Seven people }\end{array}$ & $\begin{array}{l}\text { Process: } \\
\text { Rowing } \\
\text { (solutions) }\end{array}$ & $\begin{array}{l}\text { Goal: } \\
\text { Boat } \\
\text { (current situation) }\end{array}$ & $\begin{array}{l}\text { Circumstance: } \\
\text { At the edge of waterfall }\end{array}$ \\
\hline (4) & Portugal (S) & Pay (S) & & \\
\hline (5) & Belgian (S) & & $\begin{array}{l}\text { Debt (S) } \\
\text { Load of debt (S) } \\
\text { Lack of leadership (C) }\end{array}$ & \\
\hline (6) & Spain (S) & Hang on $(\mathrm{S})$ & & \\
\hline (14) & Greece $(\mathrm{S})$ & Rescue (S) & & \\
\hline (15) & $\begin{array}{l}\text { Europe's politicians (S) } \\
\text { Illiquid governments (M) } \\
\text { German (S) } \\
\text { Insolvent countries (M) }\end{array}$ & $\begin{array}{l}\text { Create }(\mathrm{S}) \\
\text { Insistence (C) } \\
\text { Restructure (C) }\end{array}$ & $\begin{array}{l}\text { Loans }(\mathrm{H}) \\
\text { Default }(\mathrm{C})\end{array}$ & \\
\hline (19) & Spain (S) & Keep (S) & $\begin{array}{l}\text { Deep problems }(\mathrm{S}) \\
\text { A bank bail-out }(\mathrm{C}) \\
\text { Public debt }(\mathrm{H})\end{array}$ & \\
\hline (20) & $\begin{array}{l}\text { Italy }(S) \\
\text { Belgium (S) }\end{array}$ & & $\begin{array}{l}\text { High debt levels (H) } \\
\text { Ample private savings (A) } \\
\text { Underlying budgets (A) } \\
\text { Surplus (A) }\end{array}$ & \\
\hline (28) & $\begin{array}{l}\text { Euro-governments (M) } \\
\text { IMF (C) Greece (S) }\end{array}$ & $\begin{array}{l}\text { Rescue (S) } \\
\text { Restructuring (C) }\end{array}$ & & \\
\hline (32) & $\begin{array}{l}\text { Greece }(\mathrm{S}) \\
\text { Other peripherals }(\mathrm{S})\end{array}$ & Austerity plans (C) & & \\
\hline (38) & Greece $(\mathrm{S})$ & Fiscal adjustment(C) & Debt burden (S) & Peak (A) \\
\hline (39) & $\begin{array}{l}\text { Irish (S) } \\
\text { Europe (M) }\end{array}$ & $\begin{array}{l}\text { Toil (S) Service (S) } \\
\text { Pay off }(\mathrm{S})\end{array}$ & $\begin{array}{l}\text { Rescue loans (S) } \\
\text { Bondholders (C) } \\
\text { Defunct banks (C) }\end{array}$ & \\
\hline$(42)$ & $\begin{array}{l}\text { Greece }(\mathrm{S}) \\
\text { Ireland }(\mathrm{S}) \\
\text { European governments }(\mathrm{M})\end{array}$ & $\begin{array}{l}\text { Rescue (S) } \\
\text { Increase (A) }\end{array}$ & $\begin{array}{l}\text { Overall debts (S) } \\
\text { Private debts }(\mathrm{H})\end{array}$ & \\
\hline (44) & Greece $(\mathrm{S})$ & $\begin{array}{l}\text { Reduce (S) } \\
\text { Wipe out (S) }\end{array}$ & $\begin{array}{l}\text { Debt }(\mathrm{S}) \\
\text { Private bondholders(C) }\end{array}$ & \\
\hline$(48)$ & Greece $(\mathrm{S})$ & Halve (S) & Debt burden $(\mathrm{S})$ & \\
\hline (49) & Ireland (S) & Cut (S) & $\begin{array}{l}\text { Writing down bank (C) } \\
\text { Sovereign debt }(\mathrm{H})\end{array}$ & \\
\hline$(52)$ & $\begin{array}{l}\text { The ECB }(\mathrm{C}) \\
\text { Belgium (S) } \\
\text { Italy (S) } \\
\text { Spain }(\mathrm{S}) \\
\end{array}$ & Defend (S) & & \\
\hline (53) & Europe's leaders (S) & Stick to $(\mathrm{S})$ & Plan A (C) & Debt crisis (S) \\
\hline
\end{tabular}

The above table illustrates lexica-semantic correspondence between the visual mode and the verbal text. Since the verbal text does not repeat the represented participants in the sketch directly, the use of repetition is absent in this table.

As for the main seven characters in the sketch, the use of synonymy is realized by verbal words such as "Portugal, Greece, Italy, Spain, Germany, and Ireland" in correspondence with seven people, reinforcing the main text-topic in both the sketch and the verbal text concerning seven people (representing seven European countries). To further support the development of the verbal text, Meronymy has been used to show the links between seven separate countries and European countries involved in debt crisis. It is fulfilled by verbal words such as "Europe, Illiquid governments, Insolvent countries, Euro-governments, etc." indicating the place where these events happened and countries involved. The tool of Hyponymy is accomplished by words such as "Loans, Sovereign debt, Public debt, High debt levels, etc." referring to current debt situation. The use of Hyponymy also suggests that the text-topic is concerned with debt crisis of seven European countries. The tool of Antonymy is reflected by words "increase, surplus, peak, etc." indicating that the debt crisis is still a very thorny problem. These words contradict with measures taken to cut and restructure seven countries' debts. Inter-semiotic collocation use lexical items that can reasonably co-occur in a verbal text. The use of collocation is shown by words such as "restructure, default, bondholders, defunct banks, etc.", for the purpose of discussing the Plan B of restructuring their debts.

The boat is also a visual metaphor suggesting the current debt situation of seven European countries. It is the current problem that seven countries have to deal with immediately. The use of synonymy is also reflected in verbal words such as "Debt, Load of debt, Deep problems, Debt burden, Rescue loans, Overall debts, etc." It shows a clear link between the visually represented and the verbally discussed problems. Waterfall is represented the current and future debt crisis by the use of synonymy. Verbal words such as "defend, toil, cut, etc." correspond to seven people's action of rowing in the sketch. The frequent use of inter-semiotic synonymy indicates that the visual and verbal part complement each other in discussing and supporting the central topic. The use of hyponymy, meronymy, antonymy and collocation provides ample evidence with discussing debt crisis. 
Thus, combined visual represented participants with verbal words in Sample 1; ideational inter-semiotic complementarity is established between two modes.

\section{The Multimodal Characteristics of Editorials}

In order to identify the multimodal characteristics of English editorials from the perspective of ideational/representation meaning, the author also makes researches on other genres.

Compared with pictures in advertisements and posters, pictures in English editorials present different multimodal features. Advertisements and posters usually use photographs and caricatures rather than graphs. They consider pictures as the major form of expression. Advertisements and posters usually present pictures with only a few verbal sentences. As for English editorials, they give almost equal weight to the pictures and the verbal texts.

Since editorials are to explain, to judge or to comment on the hot issues, pictures in editorials can also work as a driving force to achieve editorials' purpose. Photographs in English editorials could unfold realistic events that editorials care about. They are a bit rational and objective yet they may only reveal one aspect of the main topic. Caricatures in English editorials, full of emotion, usually describe the main idea of the essay in an ironic and exaggerating way. Before reading the verbal text, the reader could analyze the caricature's plot. Then, as the reader further reads the verbal part, he would quickly grasp the sticking points in the editorial. On this occasion, caricatures usually compensate with verbal texts. They illustrate verbal texts and meanwhile exert great influence on readers' understanding. Graphs in English editorials usually associate with verbal texts in a direct way. They show the tendency of increasing or decreasing explicitly. Verbal texts usually describe the tendency in a narrative way. From graphs readers could gain major information such as variables, parameters, time, etc. and know the main topic in the verbal texts. Then, they could have a detailed analysis from the verbal texts. Thus the graphs explain and prove the verbal texts.

Based on Visual Grammar and Inter-semiotic Complementarity Framework, the paper analyzes English editorials with visual images from the perspective of ideational/representational meaning. The research not only helps readers be familiar with the nature and characteristics of multimodal editorial discourse but also gives some useful instructions to the editors so as to improve the quality of editorials.

\section{ACKNOWLEDGEMENT}

My deepest gratitude goes first and foremost to Professor Xu Zhaohui for her constant encouragement and guidance. Without her consistent instruction, this paper could not have reached its present form.

Second, I would like to express my heartfelt gratitude to the professors and teachers at Yanching Institute of Technology who have helped me a lot in the past two years.

Last my thanks would go to my beloved family and friends for their loving considerations and great confidence in me all through these years.

\section{REFERENCES}

[1] Bolivar, A. (1994). The structure of newspaper editorials. Advances in written text analysis. London: Routledge.

[2] Eco, Umberto. (1976). A theory of semiotics. Bloomington, Indiana University Press/London: Macmillan.

[3] Halliday, M.A.K. (1978). Language as a social semiotic: The social interpretation of language and meaning. London: Arnold.

[4] Halliday, M. A. K. (1994). An introduction to functional grammar (2nd Ed.). London: Edward Arnold Publishers Ltd.

[5] Kress, G. \& T. van Leeuwen. (1996). Reading images: The grammar of visual design. London: Routledge.

[6] Kress, G, \& T. van Leeuween. (2006). Reading images: The grammar of visual design (2nd Ed.). London: Routledge.

[7] Lim, F.V. (2004). Developing an integrative multi-semiotic model. K.L. O'Halloran (Ed.). Multimodal Discourse Analysis: Systemic Functional Perspectives. London and New York: Continuum.

[8] Rivers, W. L. \& McIntyre, B. (1988). Writing opinion: Editorials. Iowa: Iowa State University Press.

[9] Royce, T. (1998a). "Intersemiosis on the Page: A Metefunctional Interpretation of Composition in the Economist Magazine". Language and Beyond. P. Joret and A. Remael (Eds).Amsterdam: Rodopi.

[10] Royce, T. D. (1998b). Synergy on page: Exploring inter-semiotic complementarity in page-based multimodal text. JASFL Occasional Papers (No.1). Tokyo: Japan Association of Systemic Functional Linguistics.

[11] Royce, T. D. (2007). Inter-semiotic complementarity: A framework for multimodal discourse analysis. T. D. Royce \& W L. Bowcher (Eds.), New Directions in the Analysis of Multimodal Discourse. Mahwah, New Jersey: Lawrence Erlbaum Associates, Publishers.

[12] Spencer, M. L. (1924). Editorial writing: Ethics, policy, practice. Boston: Houghton Mifflin.

Jing Yang, born in Inner Mongolia, China, on May, 6th, 1986, is a college English teacher working in Yanching Institute of Technology in Hebei Province, China. She had studied in Xi' an International Studies University, then went to Changchun University of Science and Technology to earn her Master's degree. 
Yi Zhang, born in Wuhu, ANHUI Province, China, on August, 16th , 1987, now works in Yanching Institute of Technology in Hebei Province, China. She had studied in Anhui Normal University, then went to Zhejiang University to earn her Master's degree. 